\title{
EL FINANCIAMIENTO AGROPECUARIO EN LA REGIÓN FRONTERIZA DEL NORTE DE MÉXICO*
}

\author{
Por \\ Alfonso Andrés Cortez Lara**
}

\begin{abstract}
RESUMEN
El crédito agropecuario ha representado un factor de impulso para el desarrollo de la actividad tanto en la región fronteriza del norte de México, como en el resto del país. No obstante, el estancamiento acentuado en las últimas décadas ha sido inducido, en parte, por las políticas de financiamiento rural. En el presente documento se describe la evolución del crédito agropecuario en la región fronteriza, especialmente en el valle de Mexicali y se distingue el impacto que éste ha tenido sobre el desarrollo del sector rural. Además, se revisan las perspectivas de este instrumento como impulsor de la actividad y del mejoramiento de las condiciones económico-sociales del medio rural.
\end{abstract}

\begin{abstract}
Credit financing for farming and animal husbandry has been an incentive for the development of these industries in the northern frontier region of Mexico as well as in the rest of the country. However, the lack of growth during the last few decades has been caused, in part, by the policies of rural financing. This document describes the evolution of the credit system as applied to farming and animal husbandry in the border region, especially in the Valle de Mexicali area, and shows the impact that this has had on the development of the rural sector. In additions, there is an examination of credit as the incentive for activity and for betterment of rural-economic conditions.
\end{abstract}

\section{INTRODUCCIÓN}

El crédito dirigido a la actividad agropecuaria, tanto en la región fronteriza del norte de México, como en el resto del país, representa un factor de

* Este artículo fue recibido en enero de 1996 para su publicación en la revista Estudios Fronterizos.

** Investigador de El Colegio de la Frontera Norte, oficina coordinadora en Mexicali. 
impulso para el desarrollo de la misma. Sin embargo, el estancamiento que ha caracterizado a la actividad económica del agro, acentuado en las dos últimas décadas, ha sido inducido por las políticas específicas de mayor repercusión en la producción rural: financiamiento, precios, gasto público y comercio, que han puesto en evidencia la relación desventajosa, en los términos de intercambio, entre el sector agropecuario y el resto de la economía. A esto se suman las particularidades intrínsecas de la actividad al depender de ciclos productivos fijos y climas; a la perecibilidad de sus productos; y a la dispersión de su producción, entre otras, provocando que la generación de beneficios y ahorros sea mínima.

Ante esta situación deben analizarse nuevas estrategias y mecanismos de inversión y financiamiento, donde los instrumentos utilizados, por su diversidad y calidad, sean un soporte del crecimiento y desarrollo sostenido de la mayor proporción de productores.

Para efectos de profundizar en los elementos básicos de estudio es importante definir la función del crédito, el que se entiende como la operación que inicia con la selección del sujeto de crédito para que le sea proporcionada cierta cantidad de dinero que dispondrá, utilizará y pagará, incluyendo sus costos, de acuerdo con un plan establecido por medio de un documento legal. Asimismo, utiliza diversos mecanismos para transferir recursos a productores considerados viables para que éstos, con el concurso de otros factores y mediante la realización eficiente de sus operaciones, aumenten su bienestar y promuevan el desarrollo económico y social sin perjudicar el medio ambiente.

En este documento se realiza una descripción de la evolución del crédito agropecuario en la región norte de México, haciendo énfasis en el valle de Méxicali como una de las zonas agrícolas más importantes de la región. El propósito es distinguir el impacto que este instrumento crediticio ha tenido sobre el desarrollo del sector agrícola e identificar los factores que han influido a través de tiempo en esta evolución. Así como las características particulares que presenta el financiamiento al campo en la frontera norte con respecto al resto del país. Asimismo, se revisan las perspectivas del instrumento como impulsor de la actividad y del mejoramiento de las condiciones económicas y sociales en el medio rural en esta región.

\section{ORIGEN Y EVOLUCIÓN DEL FINANCIAMIENTO FORMAL AL CAMPO MEXICANO}

En el contexto de la gestación del proceso revolucionario de 1910, en aquel sistema dominado por las grandes explotaciones, se hacía ya necesaria la 
creación de una instancia oficial que ampliara la disponibilidad de recursos financieros. Esto motivó la fundación en 1908 de la Caja de Préstamos para Obras de Irrigación y Fomento a la Agricultura, la que enfoco sus recursos al desarrollo de propiedades donde se efectuasen obras de riego y otorgo crédito a largo plazo a través de intermediarios bancarios (Reyes, 1994). Ésta representó la primera instancia formal de apoyo financiero al agro, Cabe señalar que mientras tanto, en la región colindante con los Estados Unidos de América, se presentaban sucesos paralelos que mostraban características muy particulares de relaciones económicas y sociales entre la población de las dos naciones. Las grandes compañías extranjeras colonizadoras de tierras, constructoras, de irrigación y financieras instaladas en el suroeste de Estados Unidos, influyeron en el desarrollo de zonas agrícolas de ambos lados de la frontera como los valles de Imperial, Yuma, Mexicali y San Luis Río Colorado. Sobresale, entre otras, la participación de la Colorado River Land Company de capital estadunidense, que durante las primeras tres décadas de este siglo se apropió de grandes extensiones territoriales y derechos sobre usos de agua para iniciar procesos productivos a gran escala, sobre todo en la región del valle de Mexicali, utilizando estrategias de financiamiento y organización de la producción agrícola basada particularmente en el cultivo de algodon (Anguiano, 1995).

\section{La banca oficial del sector agropecuario}

En el nacimiento de la segunda era del agro en México, la formulación de la Ley general de instituciones de crédito y establecimientos bancarios, junto con la creación de la Comisión Nacional Bancaria, significaron la plataforma legal para la promulgación de la primera Ley de crédito agrícola el 10 de febrero de 1926, misma que dio pie a la formación de la primera entidad financiera oficial enfocada plenamente al campo, el Banco Nacional de Crédito Agrícola. A partir de ésta, se han creado alrededor de 70 más para tal fin, entre los que se cuentan 36 fideicomisos y 33 bancos (Salinas de Gortari, 1988).

El Bangrícola o BNCA. El Banco Nacional de Crédito Agrícola inicia sus actividades en 1926, su operación se caracterizó por el otorgamiento de crédito a una proporción elevada de pequeños propietarios (desde su origen y hasta $193374.4 \%$ del monto de sus préstamos a particulares, $13.8 \%$ a ejidatarios y el resto a otros).

El Banjidal o BNCE. Como consecuencia de las reformas en la legislación crediticia de 1935, se adhiere al BNCA, el Banco Nacional de Crédito Ejidal (BNCE). Las diversas fuentes con que este banco contaba, fueron la 
base para que se encauzara a satisfacer las necesidades de financiamiento de los grupos de ejidatarios organizados en sociedades locales de crédito (SLC). ${ }^{1}$ No obstante, la operación del banco en este sentido mostró incapacidad para satisfacer las necesidades individuales de ejidatarios. Por ello, en 1953 el sistema Banjidal tomó la responsabilidad exclusiva de financiar las operaciones de los productores del sector social. Se subraya que $85 \%$ del total del volumen crediticio manejado por la institución se aplicaba para cartera de crédito de avío. ${ }^{2}$ De esta manera el Bangrícola se especializó en la atención de pequeños propietarios privados.

El Banagro o BNA. El Banco Nacional Agropecuario (BNA), se crea el 8 de marzo de 1965, con el propósito de ampliar la cobertura del Estado en el financiamiento al campo, a través de la descentralización de responsabilidades sobre algunas actividades financieras del Banjidal y Bangrícola. Las operaciones crediticias del Banagro se identifican por dos grandes rasgos: a) la mayorfa de los individuos (83\%) que operaban eran ejidatarios y b) la mayor parte del crédito otorgado (59\%) era de tipo refaccionario.

El Banrural o BNCR. El Banco Nacional de Crédito Rural, surge con la. fusión de sus tres antecesores, y toma sus bases de las normas dictadas por la Ley general de crédito rural del 27 de diciembre de 1975, para otorgar financiamiento a la producción primaria, así como a las actividades complementarias de beneficio, conservación, industrialización y comercialización que estén directamente relacionadas con el sector agropecuario y que lleven a cabo los productores rurales. El resultado de la creación del sistema permitió registrar, durante sus primeros seis años de operacion, un aumento creciente en el volumen total de recursos financieros canalizados

1 De acuerdo con el artículo 45 de la Ley de crédito agricola, una sociedad local de crédito (sLC), ya sea ejidal o de pequeños propietarios, debe estar compuesta legalmente por un mínimo de diez socios. Dado que los ejidos en México se integran generalmente por más de diez individuos, es alta la probabilidad de que existieran más de una SLC en un ejido,

2 Los préstamos de habilitación o avío se destinan al financiamiento de los costos de insumos, mano de obra y servicios de la actividad primaria, de transformación, comercialización y servicios complementarios. En ocasiones se cubre el aseguramiento y la asistencia técnica. Los calendarios de ministración y plazos de amortización se establecen de acuerdo con las características de la actividad que se financia, tomando en cuenta los flujos de caja proyectados, sin exceder dichos plazos de veinticuatro meses (Ley general de instituciones de crédito).

3 Los préstamos refaccionarios se destinan a financiar la adquisición, construcción e instalación de bienes fijos y bienes de consumo duradero; así como para la formulación de proyectos, obras de infraestructura, equipamiento, insumos y otros activos o conceptos que requieran periodos de amortización mayores de veinticuatro meses y no más de 15 años, en planes de pago anuales o menores, con posibilidad de periodos de gracia. Su monto podrá llegar a $100 \%$ del costo de las inversiones (Ley general de instituciones de crédito). 
hacia al campo. La superficie agrícola babilitada se incrementó en más de $100 \%{ }^{4}$

No obstante, se observa decrecimiento de la operativa a partir de 1982 , cuando se presentan tasas de $-19 \%$ con respecto al año anterior, manteniendo esa tendencia hasta años recientes. Las limitaciones financieras y la coyuntura económica ocasionaron la distorsión en la estructura del financiamiento otorgado por el sistema Banrural. Las operaciones de éste se orientaron cada vez más a los créditos de avío y esta forma de operar es un factor que repercutió en el detrimento de la capitalización institucional, dados los grandes volúmenes de erogación y su alto riesgo de recuperación. Se señala que a partir de 1989, y en consecuencia de lo anterior, inicíó un proceso de transformación operativa y administrativa, tendiente a lograr una mayor eficiencia. Los efectos de tal reorientación en las líneas de crédito, buscando una mayor capitalización en el agro y sobre todo su recuperación institucional, se reflejó en la reducción de la superficie habilitada, volumen total de financiamiento ejercido y, en términos generales, del acceso de productores al crédito.

\section{Transformación estructural del sistema financiero agropecuario}

La crisis económica prolongada ciesde 1981, ocasionó una situación aguda en el sistema financiero de fomento, forzándolo a replantear su estructura operativa y administrativa. Al reducirse el crédito externo, hubo necesidad de recurrir con mayor intensidad a los recursos propios, lo que resultó en la racionalización del subsidio financiero que implica reclasificar clientela y modificar los patrones de acceso al crédito.

Respecto a la reducción del volumen de crédito al sector agropecuario, se destaca que en el periodo de 1981 a 1988 se presentó una reducción en términos reales de $51.6 \%$; mientras que la proporción del crédito otorgado respecto al total llegó a marcar su nivel más bajo en 1986 y en 1987 con $4 \%$ y $3 \%$ respectivamente. Esto significo un deterioro del sector agropecuario denotado con el índice global de crecimiento en los años ochenta que fue de $1.3 \%$ y que se acentuó en los últimos cinco años de esa década, con una tasa de crecimiento menor a $0.8 \%$.

Como consecuencia de la crisis económica se aceleró la reducción de dependencias oficiales no estratégicas, de esta manera, aciualmente el sistema financiero agropecuario lo integran: a) Delegaciones regionales

4 Pasó de 4.8 millones de hectáreas en 1976 a 10 millones en 1982, en este periodo el sistema Banrural participó con $49 \%$ del monto crediticio total dirigido al campo (Banco Nacional de Crédito Rural, 1986). 
del Banrural ${ }^{5}$ que constituyen la banca de primer piso y el Banco Nacional Oficina Central que funciona como banca de segundo piso, con características normativas y de control del sistema; b) Fideicomisos Instituidos en Relación con la Agricultura (FIRA), como fuente de descuento de la banca de primer piso, estas dos instancias en conjunto atienden a la población de productores en vías de consolidación del nivel de competitividad; c) Banco Nacional de Comercio Exterior (BANCOMEXT) que impulsa específicamente productos y actividades relacionadas con la exportación; d) Fondo de Capitalización e Inversiones en el sector Rural (FocIR) que se enfoca a la promoción de agroasociaciones con elementos organizativos en los que se convine la participación privada y social; e) Nacional Financiera (NAFIN), como fuente descontataria que en el sector dirige su apoyo a la promoción de agroindustrias; f) La banca comercial que presta servicio a productores rurales con un nivel de capitalización mayor con respecto a los que atiende la banca de desarrollo; y g) Instancias auxiliares de crédito e intermediarias financieras.

En el contexto de la modernización del campo, el crédito en sus diversas modalidades se considera como un instrumento de apoyo para la. capitalización de la empresa agropecuaria. Su participación en el sector agrícola observó una recuperación en términos generales, ya que la tasa promedio anual en el volumen otorgado para el periodo de 1989 a 1993 fue del $12 \%$. Sin embargo, se distingue que en este periodo la proporción que del financiamiento total de la economía se dirigí al sector agropecuario fue del $8 \%$, porcentaje que permite deducir el cambio definido en la colocación del ahorro nacional por parte del sistema bancario mexicano que presentó, en 1993, un enfoque hacia las actividades industrial y de servicios (28.24 y $38.70 \%$ respectivamente). Asimismo, las actividades como industria de transformación y de comercio cuentan con apoyo similar, en proporción al que anteriormente se otorgaba al sector agropecuario (cuadro 1).

\section{FINANCIAMIENTO AGROPECUARIO DE LA REGIÓN FRONTERIZA}

La influencia de la región fronteriza de los Estados Unidos sobre el desarrollo de la región norte de México, desde aspectos territoriales, políticos, culturales, sociales y sobre todo, en el crecimiento de las diversas

5 Desde su formación el Banco Rural se constituyó con doce delegaciones de influencia regional distribuidas en el país, mismas que se subordinan a oficinas centrales. Las regionales son las siguientes: Norte, Centro-Norte, Noroeste, Pacífico, Norte, Occidente, Centro, Pacífico Sur, Golfo, Peninsular e Istmo. 
CUADRO 1. Crédito recibido por actividad a través de las bancas de desarrollo y comercial, 1993 (miles de nuevos pesos).

\begin{tabular}{lrr}
\hline Actividades & \multicolumn{1}{c}{ Saldo $^{\mathrm{a}}$} & Proporción (\%) \\
\hline Total & 399957778 & 100.00 \\
I Primarias & 38192953 & 9.50 \\
a) Agropecuarias & 33392599 & 8.30 \\
b) Minería & 3743513 & 0.93 \\
c) Otras & 1056841 & 0.26 \\
II Industriales & 112851351 & 28.24 \\
a) Energética & 4065617 & 1.01 \\
b) Transformación & 72513892 & 18.13 \\
c) Construcción & 36271842 & 9.06 \\
III Vivienda interés social & 18568563 & 4.66 \\
IV Servicios & 154761357 & 38.70 \\
V Comercio & 75583554 & 18.90
\end{tabular}

FUENTE: Elaboración propia con datos del Banco de México, Indicadores económicos, mayo 1994.

${ }^{a} \mathrm{Al}$ mes de diciembre de 1993.

actividades económicas, ha sido siempre significativa. Dentro de las relaciones deducidas, la agricultura es una de las actividades con mayor presencia en la integración con el vecino país del norte. Algunas características de la frontera norte, inducidas por esta relación binacional son su alto porcentaje de superficie de riego, uso de tecnología y mecanización; pero además, la estructura crediticia observa particularidades originadas por tal relación.

$\mathrm{La}$ influencia del crédito como agente interactivo para el desarrollo es observable durante la crisis del algodón. El impacto que tuvo en el norte de México durante los años sesenta y setenta, la caída de los precios internacionales de la fibra blanca provocó una crisis debido a la cultura prevaleciente del monocultivo, lo que llevó a la diversificación de las cédulas de cultivos, acentuándose en los cultivos básicos y forrajeros de consumo nacional y, en menor escala, en las hortalizas de exportación. Asimismo, en el siguiente periodo comprendido de 1976 a 1982 los montos de crédito aplicados en la región promediaron anualmente $36 \%$ del total otorgado a nivel nacional. Los esquemas de financiamiento fortalecieron la diversificación de líneas. Se destaca la participación creciente de la 
banca privada en el acreditamiento de líneas de mayor rentabilidad como las hortícolas desde entonces y hasta fechas recientes, deduciendo la selectividad que sus procesos consideran para otorgar el crédito y por consecuencia el limitado acceso de productores a sus programas de financiamiento.

Por otra parte, en lo concerniente al acceso de productores del sector social al crédito se observa que en avío, durante el periodo de 1985 a 1989 , del total de productores habilitados en México la región norte absorbió una proporción de $8.4 \%$ y en 1990 ésta ascendió a 11.3\%. Del total de productores por entidad con acceso a este tipo de crédito sobresalen, particularmente, los estados de Baja California y Sonora, el primero pasó de $25 \%$ a $55 \%$ y el segundo de $13 \%$ a $40 \%$. En contraparte, en el resto de los estados decrece drásticamente. En los dos estados mencionados como los mayormente apoyados, esto representó una ampliación de cartera, pero no necesariamente una mejoría del sector, pues actualmente éstos registran los más altos índices de cartera vencida.

El comportamiento de las variables crediticias y operativas de la banca oficial circunscrita a la franja fronteriza de los estados de la región norte de México ${ }^{6}$ confirman lo anterior, sobre todo si se revisa la superficie acreditada, líneas y proyectos crediticios, en una retrospectiva de los ciclos 1989 a 1994. Los datos estimados de comportamiento global indican una disminucion de 50\% en superficie acreditada pasando de 860000 en 1989 a 349000 hectáreas en 1994. Cabe señalar que en 1991 se presentó un abatimiento que coincidio con el traspaso de cartera de la banca al Fideicomiso Liquidador de Cartera Vencida (FIDEL1Q), acción que indujo una depuración automática del padrón de sujetos de crédito, factor que influyó sobremanera para la disminución de superficie acreditada.

En términos del monto de crédito otorgađo por el sistema oficial de la región fronteriza y los estados del norte de México, en el mismo periodo, se denota el comportamiento de la tasa anual en congruencia con el análisis de superficie, mismo que muestra una tendencia a la baja con decrecimientos del orden de $15 \%$, llegando a acumular en el periodo $-77 \%$. El año fiscal de mayor abatimiento generalizado para todas las zonas lo representa 1990 con $-41 \%$. $^{7}$ Se distingue para el periodo que las zonas fronterizas de los

\footnotetext{
6 Se consideran 22 sucursales bancarias, mismas que se caracterizan por estar ubicadas en la franja fronteriza o que tienen influencia sobre los once distritos de riego en estados çolindantes con los Estados Unidos de América

El monto del crédito otorgado en un determinado año fiscal en regiones como ésta, donde predominan los ciclos alternos, se conforma generalmente con $45 \%$ del ciclo otoño-invierno anterior, $100 \%$ del ciclo primavera-verano correspondiente al año y $55 \%$ del ciclo otoño-invierno posterior.
} 
estados de Tamaulipas y Chihuahua muestran recuperación satisfactoria, al lograr incrementos anuales (a partir de 1992) en el monto de crédito ejercido, aunque no se equipara a los volúmenes de periodos anteriores (cuadro 2).

La tendencia negativa guarda una estrecha relación con el hecho de que el sistema financiero (sobre todo el oficial) haya mantenido las políticas nacionales sin considerar las especificidades de la región norte, y ello se identifica a la vez como un factor que motivó el crecimiento de la problemática del agro regional. Así, la combinación perversa del incremento de la clientela seleccionada bajo considerandos de riesgo y productividad poco efectivos; la disminución del volumen del crédito durante fines de la década anterior y principios de la presente (1990); la disminución de la inversión pública y privada en activos fijos; la promoción de actividades agrícolas y ganaderas, que del otro lado de la frontera también eran y siguen siendo apoyadas con un costo de producción menor (subsidiado) al de los productores nacionales, son en gran medida, las causas de la manifiesta descapitalizacion del sector.

Es evidente que la banca aplico el instrumento de crédito, buscando abatir sus riesgos financieros y aumentar la proporción de recuperaciones mediante el apoyo de proyectos y líneas "viables". Esta acción no fue suficiente para evitar los problemas de producción, pues la cartera vencida creció de nuevo en alta proporción sobre todo en las regiones algodoneras, dadas las condiciones externas de caída de precios internacionales.

CUADRO 2. Evolución de la superficie acreditada (avío agrícola) por el sistema Banrural en las sucuirsales bancarias de la región fronteriza del norte de México.

\begin{tabular}{lrrrrrrrrr}
\hline $\begin{array}{l}\text { Año } \\
\text { fiscal }\end{array}$ & $\begin{array}{c}\text { Total } \\
\text { F. Norte }\end{array}$ & $\begin{array}{l}\text { Tasa } \\
\text { anual }\end{array}$ & B.C. & Son. & Chih. & Coah. & N.L. & Tamps. \\
\hline 1989 & 503659 & & 76105 & 35427 & 157299 & N.D. & 117586 & 117242 \\
1990 & 272023 & -0.46 & 49251 & 34238 & 54902 & N.D. & 67025 & 66607 \\
1991 & 159948 & -0.41 & 41035 & 23820 & 29875 & 1328 & 32040 & 31850 \\
1992 & 185865 & 0.17 & 33901 & 16545 & 30867 & 2341 & 51265 & 50946 \\
1993 & 222862 & 0.20 & 39168 & 14450 & 23756 & 209 & 56413 & 56060 \\
1994 & 173003 & -0.22 & 45000 & 987 & 24456 & 400 & 50108 & 52052 \\
\hline
\end{tabular}

FUENTE: Elaboración propia con datos de gerencias generales del Norte de México, Banco Nacional de Crédito Rural, S.N.C. 
Un factor alterno de análisis es la complementariedad de los recursos financieros. Durante las décadas de 1970 y 1980 en la región por cada peso para crédito de avío (capital de trabajo), se ejerció otro para el rubro de refaccionario (inversión fija, que generalmente trae consigo desarrollo tecnologico). El plan de descuento 1992 del Fideicomiso para Crédito en Áreas de Riego y de Temporal (FICART, 1992), principal fuente descontataria del Banrural hasta 1993, ubicó en la región norte 30\% de los recursos del programa nacional, de los cuales $70 \%$ corresponden a refaccionario y el resto a crédito de avío (FICART-BANRURAL, 1992). Estos elementos evidencian que la política crediticia de complemento y diversificación en la aplicación de los recursos, que en teoría logra un mayor impacto en el desarrollo, no tuvo en la práctica el éxito esperado por el sector productivo ni por el financiero. Aunque se atribuye lo anterior a las eventualidades extemas como precios y mercado, es válido considerar que los factores "endogenos" de producción regionales tienen gran influencia en el impacto positivo de las políticas crediticias al campo. La evolución y el comportamiento de algunas variables del crédito en esta región, así como su relación con otros factores de desarrollo del sector agropecuario indican que las políticas crediticias nacionales no han distinguido cabalmente las características sui géneris de la frontera norte.

Después del auge algodonero, pilar del desarrollo de la agricultura en la frontera, se han sucedido altibajos en el desarrollo agropecuario. Como indicadores de las fallas estructurales en el diseño e instrumentación de las políticas crediticias al agro tenemos: a) Una diversificación de cultivos comercialmente exportables, presionada por la caída de precios del monocultivo implicando riesgos de comercialización, especialización y ampliación tecnológica. b) Un posterior y paulatino retiro de apoyo que, conjugado con factores externos, genera la más profunda crisis agrícola reflejada en los estados del norte en la cartera vencida más alta del país. c) Finalmente, una etapa reciente de transición donde el sistema crediticio considerado como la pieza clave para lograr la estabilidad, no ha tenido el efecto deseado en el complemento de políticas y el impulso de la actividad, salvo algunas subregiones como la Noreste (Tamaulipas) de la que se deberán aprovechar y difundir los elementos que transformaron su situación.

Sustentar el desarrollo del sector en los recursos organizativos específi$\cos$ de la región, es más efectivo que adaptar o inducir formas de producción ajenas. Esfuerzos de este tipo son los referentes a la reorganización de productores que conforman estructuras organizativas diversas con el objeto principal de facilitar el acceso al crédito. En el sector social de la frontera norte, esto se hace patente sobre todo en los estados de Baja California, Sonora y Tamaulipas. ${ }^{8}$ 
Sin embargo, es importante considerar que la rentabilidad de las líneas y/o proyectos de crédito agropecuario más bien están en función de las condiciones de intercambio prevalecientes: precios, costos y aspectos de comercialización, sin descartar como factor de peso al costo financiero, sobre todo si se compara con el de los ofrecidos al sector agropecuario del lado estadunidense.

\section{EL CRÉdTIO EN LA REgIÓN AGRÍCOLA DEL VALLE dE MEXICALI}

En el valle de Mexicali se enclava el Distrito de Riego 014, uno de los más extensos del pafs y que ocupa el cuarto lugar en importancia a nivel nacional con 207,965 hectáreas irrigables. ${ }^{10}$

El comportamiento crediticio en la zona obedece en gran medida a las variaciones descritas para la region norte en su conjunto en lo referente a disminución del volumen, diversificacion de cartera, reorganización institucional y productiva para el otorgamiento de financiamiento. Sin embargo, el valle de Mexicali conserva ciertas particularidades que lo diferencian. Durante el periodo de 1984-1994, la colocación de recursos de las diferentes instituciones mostró un comportamiento poco estable aunque con tendencia negativa de la tasa de crecimiento (cuadro 3 ).

$\mathrm{Si}$ bien es cierto que el financiamiento a las diferentes actividades productivas disminuyo, la caída del apoyo al sector agropecuario del valle de Mexicali fue aún más drástica. Posteriormente, se denota una paulatina recuperación del financiamiento total y del crédito dirigido al agro, observando además para ese periodo que el incremento promedio anual del monto de cartera agropecuaria en términos reales fue $9.2 \%$, mientras que la cartera de financiamiento total aumentó en promedio $18.5 \%$, lo que evidencia el retiro del financiamiento al sector agropecuario local, mismo que en los primeros años del periodo de análisis absorbio $46 \%$ de la cartera total, una proporción significativa, si se compara con el 14\% de los últimos años del periodo. Adicionalmente, la oferta crediticia del sistema bancario de Mexicali aumentó anualmente tres veces más que su propia captación

8 La encuesta de Tipología de Productores (SARH-CEPAL,1992), arrojó que la región norte de México, en promedio $57 \%$ de los productores del sector social, está organizado y $69 \%$ de ellos lo hace con el fin de obtener crédito.

Amador Ramírez (1992), determina que el costo financiero del crédito es considerado un factor interno significativo dentro de los costos de producción de los cultivos. En el valle de Mexicali, tal costo en promedio para granos básicos, forrajes y oleaginosas representa $10 \%$. Para hortalizas es aún más su peso y oscila entre $11 \%$ y $20 \%$, que comparado con los productores del otro lado de la frontera, dicha proporción es de 2 a 3 veces mayor.

Información de la Comisión Nacional del Agua, Gereacia Estatal en Baja California, 1994. 
y este déficit fue compensado por otras plazas sin incluir en sus colocaciones al sector agropecuario.

En el marco del crédito oficial, un aspecto que debe subrayarse es el del cambio tipologico de financiamiento. Se denotan incrementos porcentuales en inversion fija y una tendencia a colocar proporciones importantes del monto para conceptos no tradicionales. El acreditamiento para activos fijos tuvo una gran promoción y ello se distingue en el monto y número de proyectos de inversión caracterizados por bienes duraderos como maquinaria y equipo, obras hidroagricolas y crecimiento de hatos ganaderos.

El monto para crédito refaccionario presenta un incremento anual promedio de $65 \%$ y se fundamenta en la operación del programa de Proyectos Integrales de Desarrollo, que contemplaba el otorgamiento de paquetes crediticios articulados (avio y refaccionarios). Sin embargo, los resultados de este programa no fueron del todo satisfactorios, pues no se cumplio cabalmente y tampoco tuvo una amplia promoción, o en su caso, ésta no fue aceptada por los productores quienes encontraron dificultades en la organización para producir.

CUADRO 3. Financiamiento del sistema local para la actividad agropecuaria del valle de Mexicali.

\begin{tabular}{|c|c|c|c|c|c|c|c|}
\hline \multirow[t]{2}{*}{ Año ${ }^{2}$} & \multicolumn{2}{|c|}{$\begin{array}{l}\text { Financ. agropecuario } \\
\text { (millones de pesos) }\end{array}$} & \multirow[t]{2}{*}{$\begin{array}{c}\text { Tasa } \\
\%\end{array}$} & \multicolumn{2}{|c|}{$\begin{array}{l}\text { Financiamiento total } \\
\text { (millones de pesos) }\end{array}$} & \multirow[t]{2}{*}{$\begin{array}{c}\text { Tasa } \\
\%\end{array}$} & \multirow[t]{2}{*}{$\begin{array}{l}\text { Relación } \\
\text { Agro/Tota }\end{array}$} \\
\hline & corrientes & constantes $^{c}$ & & corrientes & constantes & & \\
\hline 1984 & 12943.4 & 1683.8 & & 30346.6 & 3950.1 & & .43 \\
\hline 1985 & 39916.4 & 3300.0 & 95.9 & 74961.1 & 6197.3 & 56.9 & .53 \\
\hline 1986 & 46185.0 & 2009.7 & -39.1 & 93786.0 & 4081.1 & -34.1 & .49 \\
\hline 1987 & 86766.0 & 1522.8 & -24.2 & 186622.0 & 3275.4 & -19.7 & .46 \\
\hline 1988 & 152864.0 & 1357.6 & -10.8 & 382396.0 & 3396.1 & 3.7 & .40 \\
\hline 1989 & 132082.0 & 996.2 & -26.6 & 565647.0 & 4266.4 & 25.6 & .23 \\
\hline 1990 & 176833.0 & 1115.5 & 11.9 & 855460.0 & 5396.4 & 26.5 & .21 \\
\hline 1991 & 278271.2 & 1522.5 & 36.5 & 1730218.0 & 9466.2 & 75.4 & .16 \\
\hline 1992 & 270603.8 & 1331.4 & -12.6 & 2566210.0 & 12625.9 & 33.4 & .11 \\
\hline 1993 & 504040.2 & 2217.7 & 66.6 & 3420215.0 & 15048.4 & 19.2 & .15 \\
\hline $1994^{\mathrm{b}}$ & 499922.7 & 2083.0 & & 3525975.0 & 14691.6 & & .14 \\
\hline
\end{tabular}

FUENTE: Elaboración propia a partir de datos del Centro Bancario de Mexicali, A.C.

a Saldos a diciembre de cada año incluyendo cartera vigente, vencida y reestructuraciones.

${ }^{b}$ Saldos a febrero

${ }^{c}$ Pesos deflactados con el Indice Nacional de Precios general de Mexicali, $1980=100$. 
En sentido opuesto para el mismo periodo, comparando los subciclos homólogos, la superficie habilitada registró una reducción anual promedio para primavera-verano de $40 \%$ y de $15 \%$ para el subciclo otoño-invierno.

Es importante acotar que uno de los factores de mayor influencia sobre el éxito de los proyectos, es sin duda el cumplimiento de indicadores de calidad en cartera de crédito.

Un estudio realizado en 1993 para identificar tal factor, muestra a la vez la situación del agro ante el sistema crediticio en general, Los proyectos de inversión se clasificaron en primera instancia como "normales" cuando: a) los ingresos al productor fueran iguales o mayores a las expectativas, b) las recuperaciones del banco fueran mayores o iguales a las programadas y, c) los activos generados mayores a los proyectados. Se consideraron deficientes si no cumplían con los estándares técnicos establecidos. Con dichas bases se encontró que $32 \%$ de los casos revisados se ubicaron en algún grado de deficiencia, jerarquizados según la frecuencia con que se presento el factor causal. ${ }^{1}$

En estas deficiencias se refleja la problemática crediticia del sector agropecuario del valle de Mexicali. En primer término se observa lo que se menciona como la "deficiencia tradicional", que es la inoportunidad del crédito sobre todo en el sistema oficial. Sin embargo, aquí es importante señalar el hecho de que los recursos que se reciben fuera de tiempo por el productor no representan una causa atribuible totalmente a los oferentes, ya que en ocasiones la solicitud de crédito se presenta de manera extemporánea, situación que repercute en los resultados cuantitativos referidos a la rentabilidad de la empresa al incrementarse los costos de producción y desfazar fechas óptimas de siembra y de cosecha. Después del anterior, los tres problemas básicos que presenta el sector agropecuario lo constituyen las mermas de producción, los precios bajos y la comercialización deficiente, aspectos que afectan a una tercera parte de las empresas productivas (cuadro 4).

Es posible deducir que estas son las causas elementales que desencadenan la reducción de ingresos al productor y en consecuencia, el incremento de probabilidad de generar cartera vencida.

Respecto a la deficiencia detectada en relación con la asistencia técnica, donde $8 \%$ de los casos revisados mostraron problemas, es importante

\footnotetext{
${ }^{11}$ El reporte de supervisión y encuesta al productor realizada por la subdelegación en Baja California del FCART, contempló una muestra aleatoria de proyectos descontados en las sucursales bancarias del sistema dentro de la región del valle de Mexicali. FCAKT tenía actividades de descuento con el Banrural ( $90 \%$ de los créditos) y por tal razón daba seguimiento a los proyectos, para que en caso de un mal funcionamiento se realizara el rescate de los financiamientos.
} 
CUADRO 4. Jerarquización de deficiencias detectadas en los créditos otorgados por el sistema Banrural (1993).

\begin{tabular}{clc}
\hline $\begin{array}{c}\text { Orden } \\
(\%)\end{array}$ & Deficiencia detectada & Proporción \\
\hline 1 & Crédito inoportuno & 58 \\
2 & Producción inadecuada & 38 \\
3 & Comercialización problemática & 30 \\
4 & Siniestralidad excesiva & 28 \\
5 & Aseguramiento problemático & 28 \\
6 & Ingresos netos menores & 27 \\
7 & Cartera vencida & 20 \\
8 & Inversiones fijas inadecuadas & 20 \\
9 & Recuperaciones menores de banco & 15 \\
10 & Crédito insuficiente & 11 \\
11 & Asistencia técnica deficiente & 8 \\
\hline
\end{tabular}

FUENTE: Elaboración propia con datos del Fideicomiso para Crédito en Áreas de Riego y de Temporal, Subdelegación Mexicali, 1993.

mencionar que aunque no es el principal, sí es un factor que afecta directamente la viabilidad del proyecto, ya que brinda a la empresa soporte productivo con base en la elaboración y conducción del proyecto, aspectos organizacionales, concertación y obtención de financiamiento, adquisición de insumos y rubros de inversión, proceso productivo, comercialización y administración de la empresa.

Por otra parte, un estudio realizado en el sector ejidal del valle de Mexicali en 1994 y verificado en los módulos 15 y 16 del distrito de riego entre productores privados y ejidatarios en 1995, contempló temas generales y específicos que se relacionan con la actividad rural, como son el Tratado de Libre Comercio, organización para la producción, crédito, tenencia de la tierra y costos sociales de la unidad de producción. Los resultados arrojados confirman y validan el estudio oficial antes mencionado en lo que respecta a la situación crediticia. ${ }^{12}$

${ }^{12}$ Encuesta "Impactos de las reformas al artículo 27 constitucional en la producción y productividad del sector ejidal en el valle de Mexicali". El Colegio de la Frontera Norte Michigan State University-C.P., 1994-1995. 
Particularmente, la sección de crédito se compone de una cédula que considera los aspectos de disponibilidad y uso del recurso financiero, suficiencia, costo, oportunidad, tramitología e impactos directos en la actividad, cuyos resultados describen los matices del problema crediticio a nivel local.

De esta forma se realiza el comparativo de los años 1988 y $1994^{13}$ y se obtiene que para el primer año, en cuanto a cobertura, $76 \%$ de los productores contaban con algún tipo de apoyo financiero para realizar las actividades y el restante $24 \%$ aplicaba recursos propios. La principal instancia financiera de los acreditados era Banrural que apoyaba a $75 \%$ de la cartera total agropecuaria, muy por arriba de otras como la banca comercial e instituciones auxiliares. Para 1994, la situacion cambia en algunos aspectos, $57 \%$ tiene algún tipo de apoyo financiero predominando el Banrural como acreedor con $92 \%$ del total de los acreditados. Esto muestra la tendencia a la disminución de la cartera agropecuaria del sector social en $20 \%$.

Por otra parte, se distinguen cuáles fueron las principales causas del abatimiento, encontrando que $33 \%$ de los productores que dejaron de contar con apoyo crediticio manifestó inconveniencia en costos financieros y 20\% no cumplían satisfactoriamente con los requisitos de las instituciones financieras, principalmente las referentes a garantías y antecedentes negativos en la clasificación de su cartera, que por ende mostraron inviabilidad como sujetos de crédito.

En lo relativo a la efectividad del servicio de financiamiento actual, $58 \%$ consideró insuficientes las cuotas de crédito otorgadas para cubrir los costos de operación representando en la mayoría de los casos sólo tres cuartas partes de sus necesidades reales, dadas las condiciones de aumento en los costos de producción o en su caso de los rubros de inversión que convierten en inadecuadas las cuotas del banco. En términos de oportunidad de ministraciones, se indica que $42 \%$ de los créditos se aplican de manera desfasada y surten un efecto directo en el desplazamiento de labores de preparacion, fechas de siembra fuera de las optimas recomendadas y aumento de riesgos en mermas por bajos rendimientos.

La tramitología es un indicador más de la eficiencia institucional. Al respecto, se encontró que $43 \%$ de los acreditados por las instituciones financieras expresaron falta de agilidad, soportada básicamente en el exceso de requisitos y la lentitud del personal para atender y resolver sus

${ }^{13}$ En 1988 se consideraron los ciclos productivos P-V 88/88, perennes 88 y O-I 88/89; para 1994 se refieren los ciclos P.V 94/94, perennes 93 y O-1 93/94. 
solicitudes, sobre todo en la banca oficial. En términos generales, comparativamente los años mencionados muestran significativas variaciones, ello se refleja con lo anterior, además de la respuesta expresa sobre la evolución del sistema financiero donde $48 \%$ de los acreditados indic 6 que el servicio ofrecido había empeorado, $19 \%$ manifiesta que no hubo ningún cambio significativo y menos de $10 \%$ encuentra una mejora.

El estudio oficial y el levantamiento de campo a que se hace mención permitieron distinguir la problemática, desde factores externos como los precios, hasta los internos como la inoportunidad del crédito, limitantes de asistencia técnica y de aspectos organizativos para la producción. Este último aspecto es factor adicional de peso específico ligado a la eficiencia e impacto del financiamiento y se denota que no ha sido del todo atendido con la intensidad que requieren las condiciones organizativas en que se encuentra el sector agrario regional, ${ }^{14}$ a pesar de sus potenciales características integradoras para la producción, dejando a un gran número de productores por esta causa sin acceso al financiamiento por estar fuera del universo de sujetos de crédito.

Al respecto, la Ley agraria recoge de la antigua Ley de crédito rural, un aspecto significativo en cuanto a la regulación de las sociedades rurales, donde se estipula que los ejidatarios y propietarios rurales privados pueden formar sociedades para optimizar el aprovechamiento de recursos físicos, procesos de comercialización y transformación de productos y prestación de servicios que permitan el mejor desarrollo de las actividades. ${ }^{15}$ Aunque en teoría esto representa ampliar la gama de posibilidades para crear nuevas formas de asociamiento e incrementar así el universo de sujetos de crédito, en la práctica no se ha logrado.

\section{Las instituciones auxiliares de crédito agropecuario}

En el valle de Mexicali podemos percibir ligeramente la presencia de instituciones auxiliares de crédito agropecuario. En 1992 se constituy6 la Unión de Crédito Agroindustrial y Comercial de Mexicali, S.A. de C.V, compuesta por 58 socios accionistas, una sociedad cooperativa, tres empresas particulares y una sociedad de producción rural. No obstante, la actividad operativa crediticia no ha sido consistente, lo que representa un

\footnotetext{
14 En Baja California operan menos de la mitad de las organizaciones económico-productivas que existían, inclusive antes de las modificaciones legales (Delegación Estatal de la SRA, 1994, citado por Zavala, J., 1994).

Las figuras existentes antes de las modificaciones a la ley mantienen el reconocimiento legal, pero además se consideran dos nuevas: las sociedades de solidaridad social y las asociaciones en participación regidas por esquemas del derecho mercantil.
} 
retroceso, ya que si bien en términos legales se ha dado la apertura para la instalación de estas instancias con el fin de que promuevan la organización y administración de empresas comercializadoras y reciban depósitos de sus socios y préstamos de entidades financieras del exterior, también es cierto que no se han aprovechado óptimamente sus ventajas.

Dado el impacto local tan reducido que estas instancias han tenido, particularmente en lo referente a las actividades agropecuarias, se hace necesario considerar el análisis de la participación de instituciones auxiliares de crédito especializadas en el agro del otro lado de la frontera local, donde geográficamente la región del valle de Mexicali se integra a los factores de desarrollo económico y social. De esta manera, la Farm Credit Services Southwest a través de sus tres oficinas regionales: Arizona Agricultural Credit Association (AACA), Imperial-Yuma Production Credit Association (PCA) y Federal Land Bank Association of El Centro (FLBA), opera con funciones equiparables a las de uniones de crédito, con accionistas agropecuarios de zonas aledañas. ${ }^{16}$ Su actividad ofrece balances positivos en cuanto a crecimiento de cartera, activos, capital y recuperaciones. Se observa la tendencia por elevar o mantener la calidad de su cartera de crédito y reducir el riesgo de la misma a través de la implementación de programas de Calidad Total (TQM). Es importante destacar la consistencia de estas instancias crediticias estadunidenses que mantienen sus carteras de acuerdo con la rentabilidad expresa de la misma, basada en asegurar su calidad.

Esto permite intuir la importancia de la microrregión en el contexto nacional, en cuanto a infraestructura productiva. Sin embargo, el valle de Mexicali, pese a su ubicación estratégica, no ha escapado de las situaciones adversas que presentan las zonas agrícolas del país en general y a los efectos negativos de las transformaciones recientes en torno a las políticas de apoyo al campo. El retiro de los apoyos tradicionales, incluyendo el crediticio traducido en reducción de cartera agropecuaria en monto, superficie y sujetos, son los efectos de la transformación operativa de la banca oficial. Por otra parte, la orientación financiera, principalmente de la banca privada hacia otras actividades productivas más redituables, ban inducido en conjunto la urgente necesidad de reorganización de los productores (aspecto que representa un foco rojo) para crear nuevas alternativas. Las condiciones de competitividad y productividad implícitas en el contexto de la apertura comercial requieren considerar nuevos y diversos esquemas

16 AACA circunscribe a los condados de Maricopa, Pinal, Navajo y Graham principalmente; PCA a Imperial y Yuma y f.BA a los de Imperial, Yuma y La Paz. 
financieros y de organización para producir. Al respecto, es importante comentar el impacto que sobre la actividad tienen las fuentes crediticias del otro lado de la frontera, que introducen estándares de calidad de operación y cartera crediticia, aspecto que los ubica en situación competitiva favorable respecto a sus homólogos en la frontera norte de México y particularmente, del valle de Mexicali.

\section{Modelo conceptual para incrementar la eficiencia del credito al agro}

La disponibilidad y los costos del crédito como factor fundamental de producción, por más favorables que sean, no garantizan que la ventaja competitiva sea real y sostenible. Lo importante es considerar el proceso permanente de innovación y de generación de mejoras. De esta manera, se requiere de la instrumentación de políticas de crédito que satisfagan los requerimientos que en calidad y cantidad son indispensables para mejorar las condiciones del sector productivo y así aumentar las posibilidades de transitar en el ámbito de la competitividad internacional.

Algunas estrategias que se ajustan a tales situaciones se plantean como. alternativas a la problemática regional del crédito.

a) Desarrollo de entidades financieras de apoyo al sector agropecuario (parafinancieras).

La entidad parafinanciera, así denominada por los principales promotores del sistema crediticio rural (FIRA), representa una estructura organizativa enclavada en el sector que puede ser constituida por una diversidad de entes o empresas relacionadas con productores y que desarrolla funciones complementarias de la banca como pueden ser: a) selección de sujetos de crédito, b) aval y, c) operación (administración, distribución, supervisión y recuperación) del financiamiento. El patrón tradicional de cultivos en el valle de Mexicali lo reconoce como zona de alta productividad natural de algodón en primavera-verano y trigo en el ciclo alterno. La infraestructura instalada y las empresas constituidas como entes parafinancieros, representan el potencial para dar soporte a los productores y viabilidad a los cultivos

b) Diversificación de entidades no bancarias.

Fondos de autoaseguramiento y fideicomisos: $\mathrm{Al}$ estar trabajando en un grupo organizado se facilita la constitución de estructuras operativas. El autoaseguramiento es un sistema en el que los grupos depositan cuotas, 
de esta manera, al autoadministrar el recurso se pueden abatir significativamente los costos y ampliar y diversificar la cobertura de riesgos. Los fideicomisos pudieran apoyarse en el sistema bancario para incrementar su capital y autofinanciarse a un costo menor que los ofrecidos normalmente y que pudiera lograr un costo financiero con un valor proporcional a 97\% de Certificados de la Tesorería (CETES), a la vez que se crean las condiciones para la ampliación y diversificación de la cobertura de riesgos. ${ }^{17}$

Cajas de ahorro y uniones de crédito: Como se ha mencionado con anterioridad, éstas tienen actividad incipiente en la región y será necesario aumentar su operativa para contar con más y mejores opciones que en términos generales busquen abatir costos financieros.

Considerando el esquema empresarial, las uniones de crédito como intermediarios financieros ofrecen una serie de ventajas. Estas organizaciones auxiliares que agrupan a personas físicas y morales bajo la modalidad de Sociedad Anónima de Capital Variable buscan, por medio de la cooperación, optimizar su capacidad de negociación y poder así resolver necesidades financieras en forma directa: facilitar el acceso crediticio a los socios, prestar garantía y/o aval en los créditos que éstos contraten; apoyar la adquisición de materias primas, insumos y maquinaria; realizar acciones conjuntas en materia de industrializacion y comercialización de productos.

No obstante lo anterior, las condiciones económicas y organizativas limitadas prevalecientes en el sector rural inhiben el desarrollo de estas instancias. El marco legal exige como requisito mínimo de capital un monto elevado (1.5 millones de nuevos pesos), factor que representa una barrera difícil, máxime si se conjuga con el aspecto organizativo de poco arraigo cultural. El éxito de estas entidades radica en gran parte en la calidad de la administración, el conocimiento personalizado y preciso de sus socios y de sus garantías, que en consecuencia inducen la baja proporción de cartera vencida generada.

c) Aplicación de estrategias operativas para el otorgamiento del crédito.

Es necesario apuntar que el funcionamiento eficiente de las altemativas financieras antes mencionadas, deben soportarse sobre bases sólidas del esquema crediticio, mismo que representa la célula básica de la mecánica operativa y que, realizada en buenos términos, brinda funcionalidad a todo

${ }^{17}$ Entrevista con directivos del Fideicomiso de Autoaseguramiento del Ejido Hermosillo y de la prospecta Unión de Crédito de la Colonia Zaragoza, en el valle de Mexicali (enero de 1995). 
el sistema financiero agropecuario. Una estrategia integral de crédito agropecuario debe considerar un propósito general: incrementar la rentabilidad de las empresas campesinas de productores, principalmente de bajos ingresos y su indicador de efectividad operativa de la estrategia crediticia sería el nivel de ingresos del productor y las recuperaciones de la entidad financiera.

El modelo para el otorgamiento del crédito que facilite el logro de tales propositos puede analizarse en cinco diferentes fases: a) planeación, b) concertación, c) operación crediticia, d) proceso productivo y e) recuperaciones. Si el proceso completo es realizado de manera optima, las posibilidades de obtener una rentabilidad adecuada aumentan y el cobro del crédito se agiliza. Es importante asentar que se aplique de buena manera la normatividad crediticia, como complemento del modelo conceptual, acoplándola a las necesidades especificas del productor y la región para mejorar sus expectativas, induciendo así la capitalización de la empresa y la disminución de la posibilidad de generar cartera vencida.

\section{COMENTARIOS FINALES}

El agro de la región norte de México muestra características distintivas en cuanto al impacto de las políticas del crédito aplicadas, particularmente trazadas por las interacciones con el vecino país. De 1960 a 1975, la región absorbió la mitad del total del monto de crédito de avío nacional y de 1976 a $198236 \%$ en promedio. En periodo reciente, la cobertura medida en superficie habilitada en años fiscales, la región alcanzó proporciones promedio de $25 \%$ respecto al total nacional, denotándose el predominio de cultivos del subciclo otoño-invierno.

En lo que respecta al valle de Mexicali, durante los últimos diez años, la tasa de colocación de recursos de instituciones privadas y oficiales mostró una tendencia general negativa enfatizada en el sector agropecuario en las diferentes actividades productivas. $\mathrm{El}$ incremento promedio anual del monto de cartera agropecuaria en términos reales fue $9.2 \%$, mientras que en términos globales la cartera de financiamiento total aumentó a $18.5 \%$, aspecto que evidencia el retiro del financiamiento al agro. En complemento, la tasa negativa que la captación local mostró motivó el traslado de recursos desde otras plazas, sin embargo, éstos se ubicaron en el sector industrial y comercial de la región de Mexicali, lo que indica la búsqueda por parte del sector financiero de recuperaciones sin riesgo y abatimiento de los índices de cartera vencida, apoyándose en actividades relativamente más rentables que la agropecuaria. 
Por su parte, la banca oficial busca contrarrestar la mala reputación del sector imprimiendo un rasgo distintivo a la tipología de financiamiento a través del concepto de "proyectos integrales". En el agro local se dieron incrementos porcentuales en inversión fija que para el periodo de 1989 a 1994 promediaron anualmente $60 \%$, sin embargo, no fue consistente, la causa principal fue la desorganización de los productores. Posteriormente, se busca la diversificación en el uso de los recursos, colocando una proporción de $25 \%$ del monto total para conceptos no tradicionales que pudieran dar un valor agregado al producto primario, acción aún no consolidada debido a la inexistencia de sujetos de crédito.

Al analizar los resultados de la evaluación de la calidad de los proyectos, se distinguen tres elementos centrales en la problemática crediticia del sector productivo agropecuario: a)internos, soportados en las mermas de la producción y obtención de bajos rendimientos; b) externos, representados por las limitantes de mercado y precios; y c) institucionales, donde especfficamente el sector financiero (oficial) aún presenta deficiencias en el otorgamiento de créditos.

Los efectos directos fueron la pérdida de rentabilidad en la actividad y el crecimiento de la cartera vencida. Aunque el diagnóstico fue parcial e inicial, permite vislumbrar para la zona algunas acciones que se promovieron con el propósito de revertir la situación. Por un lado, la organización de productores en figuras innovadoras para aprovechar potencialidades de grupo y, por otro, la formación de instituciones auxiliares de crédito. No obstante, ni una ni otra medida han logrado impactos significativos, aunque en la vecina área agrícola (Valle Imperial, en Califomia, Estados Unidos) se observan las ventajas que obtienen los productores de este tipo de acciones, pero además se distingue el éxito de estas entidades (FCSS) que muestran máximas recuperaciones, mínima cartera vencida y crecimiento lento pero sostenido de cartera agropecuaria, basado ello en estrategias de calidad total tanto hacia el sector productivo como intrainstitucional.

$\mathrm{La}$ importancia que el apoyo financiero tiene sobre el desarrollo de la actividad agropecuaria es palpable, se puede afirmar entonces que en la medida que se complementen los factores de ampliación de volumen y cartera con procesos adecuados de selección de sujetos por parte de la banca, se consoliden las auxiliares de crédito y se organicen los productores en formas asociativas de responsabilidad financiera compartida, se estará en mejores condiciones de plantear esquemas productivos de competencia con el exterior y de dirigir la producción para satisfacer demandas internas, ampliando las posibilidades de elevar el nivel de vida del medio rural. 
Una nueva cultura supone un cambio mental básico y pasar de la perspectiva de corto plazo a una de horizontes amplios. La concepcion agricola tradicional es que un ciclo productivo es determinante. Ahora hay que inscribir el desarrollo del sector en una política productiva a largo plazo. Esto presupone cambios fundamentales en la organización de las empresas agropecuarias y en los mecanismos financieros de apoyo a su capitalizacion. Sin embargo, lo anterior debe ser antecedido por una reactivación del campo que implica la modificación de las condiciones desventajosas de los términos de intercambio, lo que significa un viraje en el contenido e implementación de las distintas políticas dirigidas al sector rural, principalmente la que nos ocupa, la del financiamiento. La instauración de nuevos enfoques y mentalidades en la actividad y en las instituciones concurrentes, básicamente financieras, así como en los mismos productores, son acciones complementarias que darán permanencia y efectividad a las políticas crediticias.

\section{BIBLIOGRAFIA}

ALVARNOZ, A. 1985. Trayectoria y ritmo del crédito agrícola en México, Ed. Trillas, México.

AMADOR R., F. 1992. "Ventaja comparativa de la producción agrícola de Baja California, México", tesis de maestria, Centro de Economía del Colegio de Postgraduados, Montecillo, México.

ANGUIANO Téllez, Maria Eugenia. 1995. Agricultura y migración en el valle de Mexicali, El Colegio de la Frontera Norte, Tijuana, B.C., México.

Banco Nacional de Crédito Rural. 1986. Sesenta años de apoyo al campo, Ed. LIMUSA, México.

CALVA, José Luis. 1991. "La inversión privada, social y pública en el sector agropecuario", en Memoria del Congreso Nacional sobre la Modernización del Campo Mexicano, CIDAC, INCA-RURAL, Fundación Konrad Adenauer y FMDR, México, 1991.

Centro Bancario de Mexicali, 1994, "Registro de cartera agropecuaria", Mexicali, B.C., México.

CEPAL. 1982. Economía campesina y agricultura empresarial (Tipologia de productores del agro mexicano), Siglo Xxi Editores, México.

DE LA MORA Gómez, J. 1990. "La banca de desarrollo en la modernización del campo", en Comercio Exterior, vol. 40, núm. 10, México. 
Farm Credit Services Southwest. 1994. Annual Report (1989-1993), El Centro, Ca. EUA.

FICART-BANRURAL. 1992. "Sistema de indicadores de la operación de crédito y descuento refaccionario", México.

- 1993. "Reporte de supervisión de la región Noroeste 1992", Mexicali, B.C., México.

FICART, Subdelegación Mexicali. 1992. "Datos básicos 1992”, Mexicali, B.C., México.

RANFLA G., Arturo.1986. “La producción agrícola fronteriza 1977-1981: Un análisis estructural", en Estudios Fronterizos, año III vol. III, núm. 9, IIS-UABC, Mexicali, B.C., México.

REYES, O. S., et al. 1994. Estructura agraria y desarrollo agrícola en México, Fondo de Cultura Económica, México.

ROCHAC, A. 1956. El crédito agrícola. Salvat Editores, S.A. Barcelona, España.

ROMÁN Calleros, J. 1990. "Origen y desarrollo de dos áreas de riego", Cuadernos COLEF. El Colegio de la Frontera Norte, Tijuana, B.C. SARH-COPAL. 1992. "Primer informe de tipología de productores", México.

SALINAS DE G., Raúl. 1988. Agrarismo y agricultura en México independiente y postrevolucionario, FCE, México.

ZAVALA, José. 1994. "Algunas consideraciones sobre la organización económica del sector rural en B.C.", en Memoria de la tercera evaluación externa COLEF III, Tijuana, B.C. 